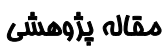

\section{اندازه كيرى ميزان شدت يرتو فرابنفى نوع A كيهانى در شهر بجنورد}

\author{
رجبعلى حكمم آبادى '*، اسماعيل شجاعُ \\ ' كارشناسى ارشد بهداشت حرفه اى، عضو هئيت علمى دانشكده بهداشت، دانشخاه علوم يزشكى خراسان شمالى، بجنورد، ايران

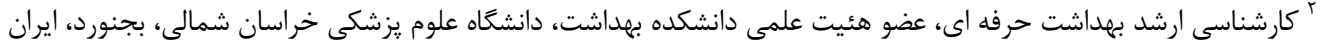

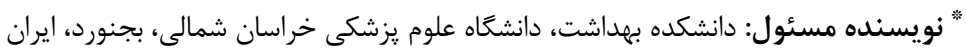

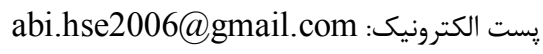

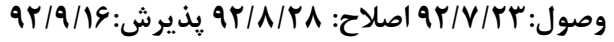

زمينه و هدف: مهمترين منبع طبيعى توليد /شعه ماوراء بنفش، خورشيد است و مواجهه با اشعه ماوراء بنفش باعث بروز اثرات مضر بر

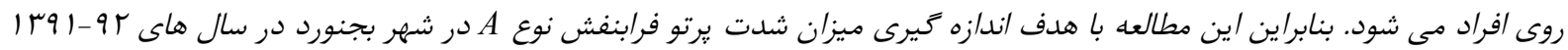
انجام كرفت. مواد و روش كار: در /ين مطالعه توصيفى - مقطعى، ميزان شدت برتو فرابنفش نوع A با استفاده /ز دستعاه راديومتر Hagner در شهر

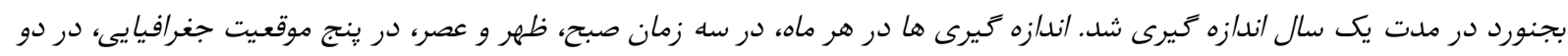

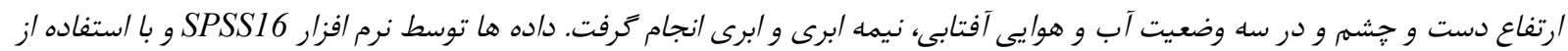

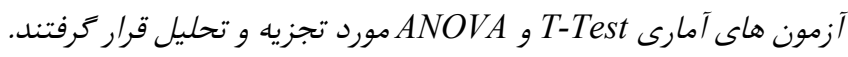

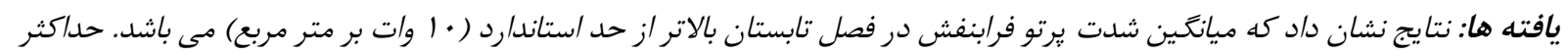

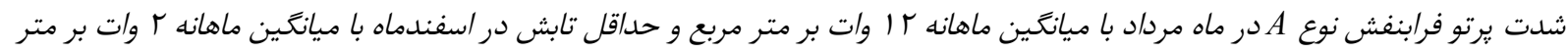

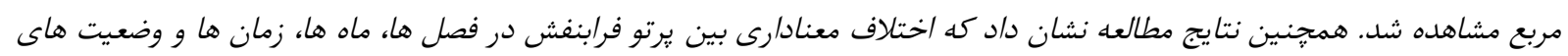

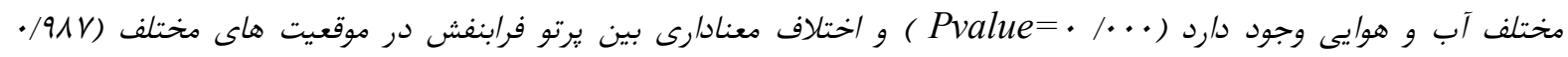
(Pvalue=

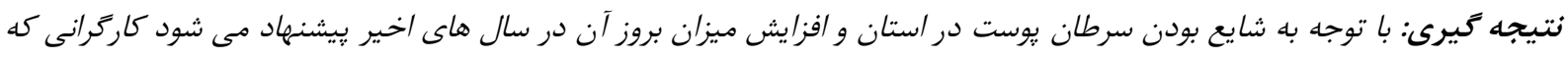

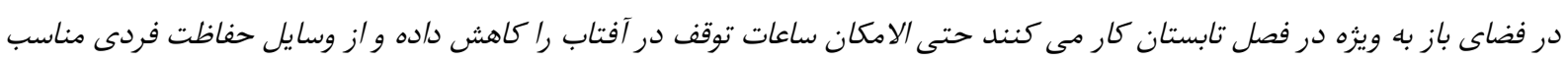

استفاده كنند.

وازه هاى كليدى: برتو فرابنفش، فرابنفش نوع A، طول موج

اشعه ماوراء بنفش، بخشى از طيف الكترومغناطيسى است

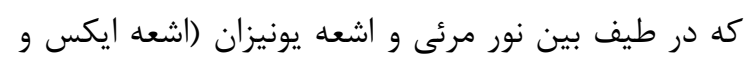

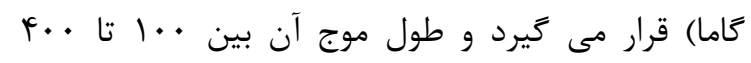
نانومتر است. اشعه فرابنفش را از نظر طول موج و تاثيرات

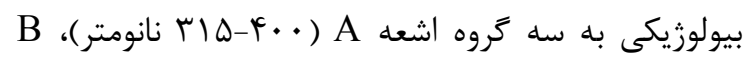

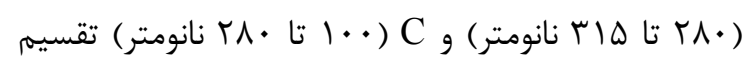
مى شوند. مواجهه با تشعشعات ماوراء بنفش باعث بروز

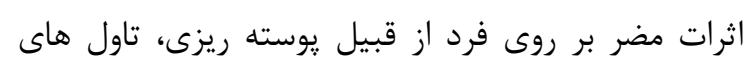
يوستى، قرمزى و تيركى يوست، سرطان يوست، كاتاراكت

\section{مقدمه}

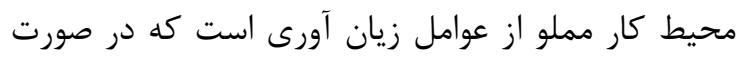

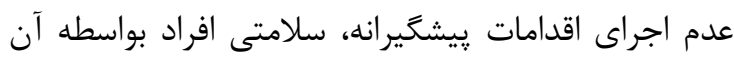

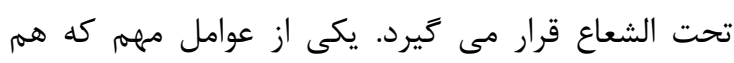

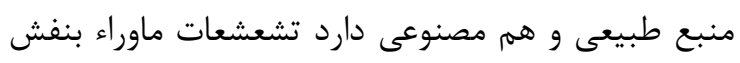

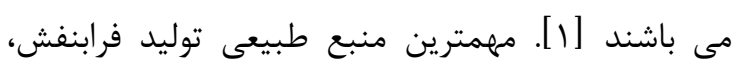

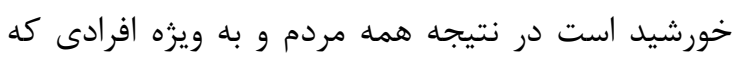

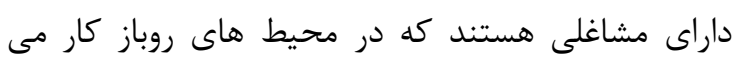

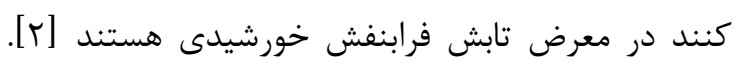


حضور اكثر افراد جامعه در معرض تابش فرابنفش در محيط هاى روباز، لزوم حفظ سلامتى آنها، شايع بودن سرطان يوست در استان، افزايش ميزان بروز سرطان

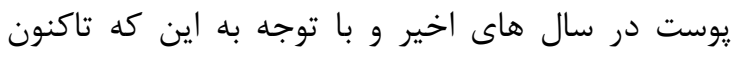
جنين اندازه كيرى در سطح شهر بجنورد انجام نكرفته

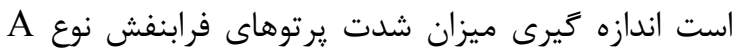
كيهانى در شهر بجنورد در ماه هاى مختلف سال ضرورى

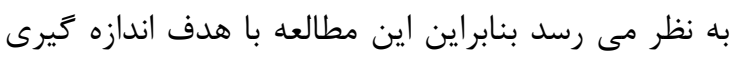

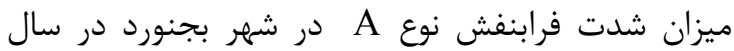

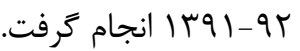

$$
\text { روش كار }
$$

در اين مطالعه توصيفى - مقطعى، ميزان تشعشعات ماوراء بنفش نوع A در •1 • ا موقعيت زمانى و مكانى با استفاده

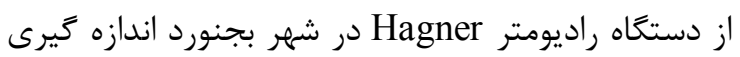

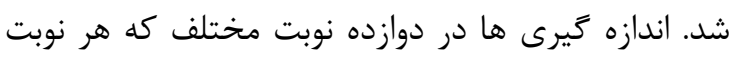

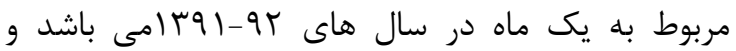

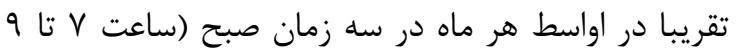

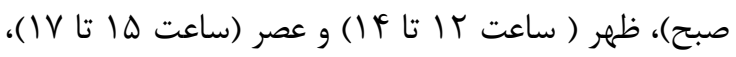
در رينج جهت جغرافيايى شمال، جنوب، شرق، غرب و آ

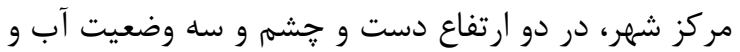

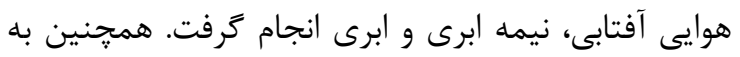

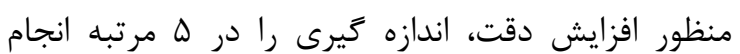

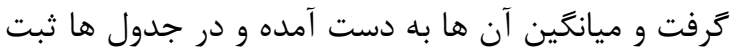

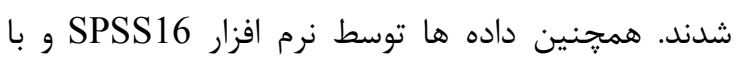

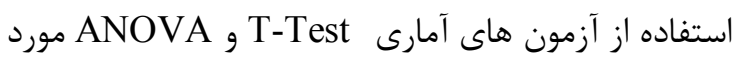
تجزيه و تحليل قرار ترفتند.

يافته ها

به طور كلى تعداد •1 • ا اندازه گيرى در جهار فصل ياييز،

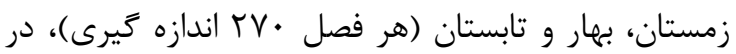
شرايط آب و هوايى مختلف آفتابى، نيمه ابرى و ابرى( هر

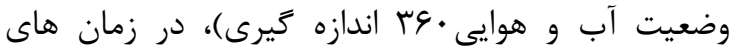

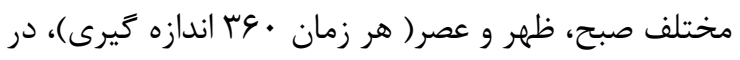

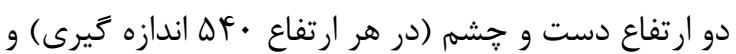

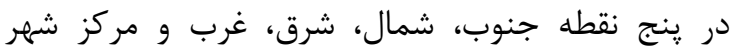
بجنورد (هر نقطه عاب اندازه كيرى) اندازه كيرى شد.

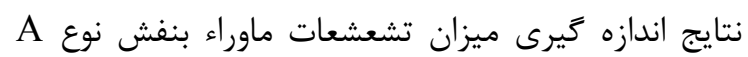

و التهاب ملتحمه و قرنيه جشم مى شود. يرتو ماوراء بنفش ايجاد واكنش فوتوشيميايى نموده و منجر به انعقاد مناد يروتئين هاى سلولى مى كردد محل و شدت اين عوارض

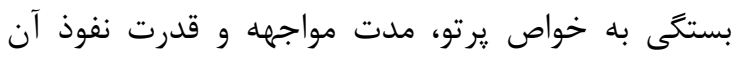

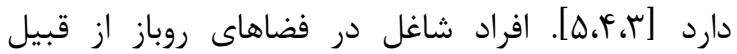

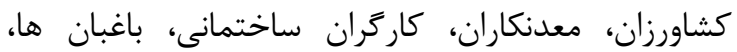

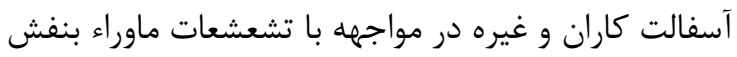

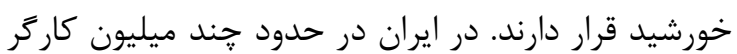

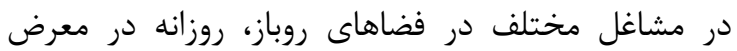

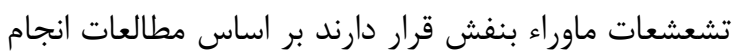

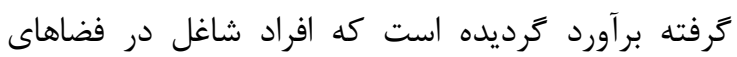

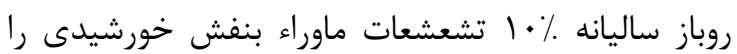
دريافت مى كنند در حالى كه افراد شاغل در فضاهاى

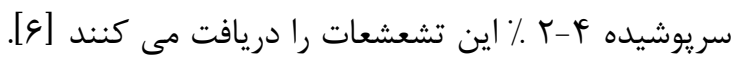
شدت تابش اشعه فرابنفش تحت تاثير عوامل متعددى از جمله زمان، ارتفاع، عرض جغرافيايى، فصل و رطوبت قرار

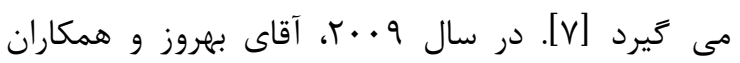

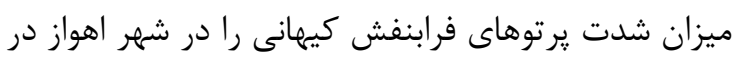
ماه هاى مختلف سال را اندازه كيرى كردند، نتايج نشان داد كه در طول روز، بيشترين شدت مات تابش اشعه ماوراء

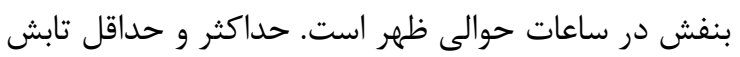
اين ترتو به ترتيب در خرداد ماه و آذر ماه مشاهده شد شدات

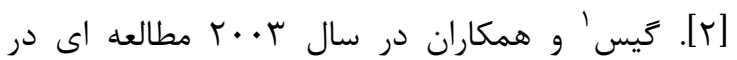

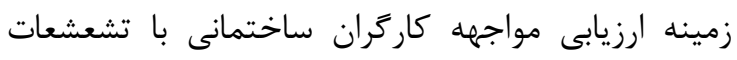
ماوراء بنفش انجام دادند و دريافتند كه در اكثر موارد

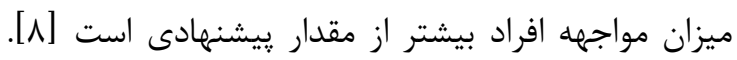

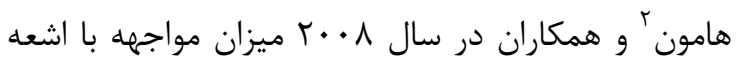

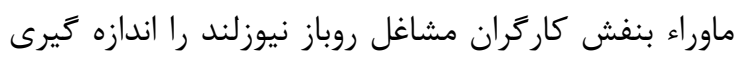

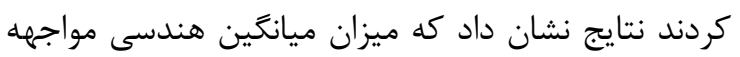

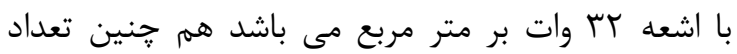

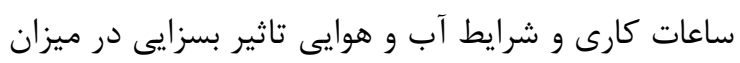

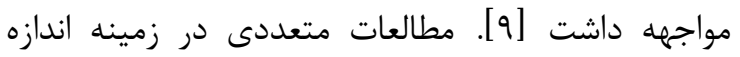
گيرى تشعشعات ماوراء بنفش خورشيد در كشورهاى

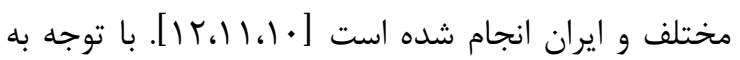

$1-$ Gies

2- Hammond 


\begin{tabular}{|c|c|c|}
\hline ميانگين مقدار اشعه بر حسب وات بر متر مربع & فصل & رديف \\
\hline$T / r \pm 1 / r$ & ياييز & 1 \\
\hline$r \pm 1 / r$ & 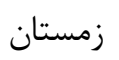 & r \\
\hline$\varphi \pm r / r$ & بهار & r \\
\hline$\| \pi \pm N / \Lambda$ & 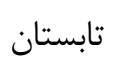 & r \\
\hline
\end{tabular}

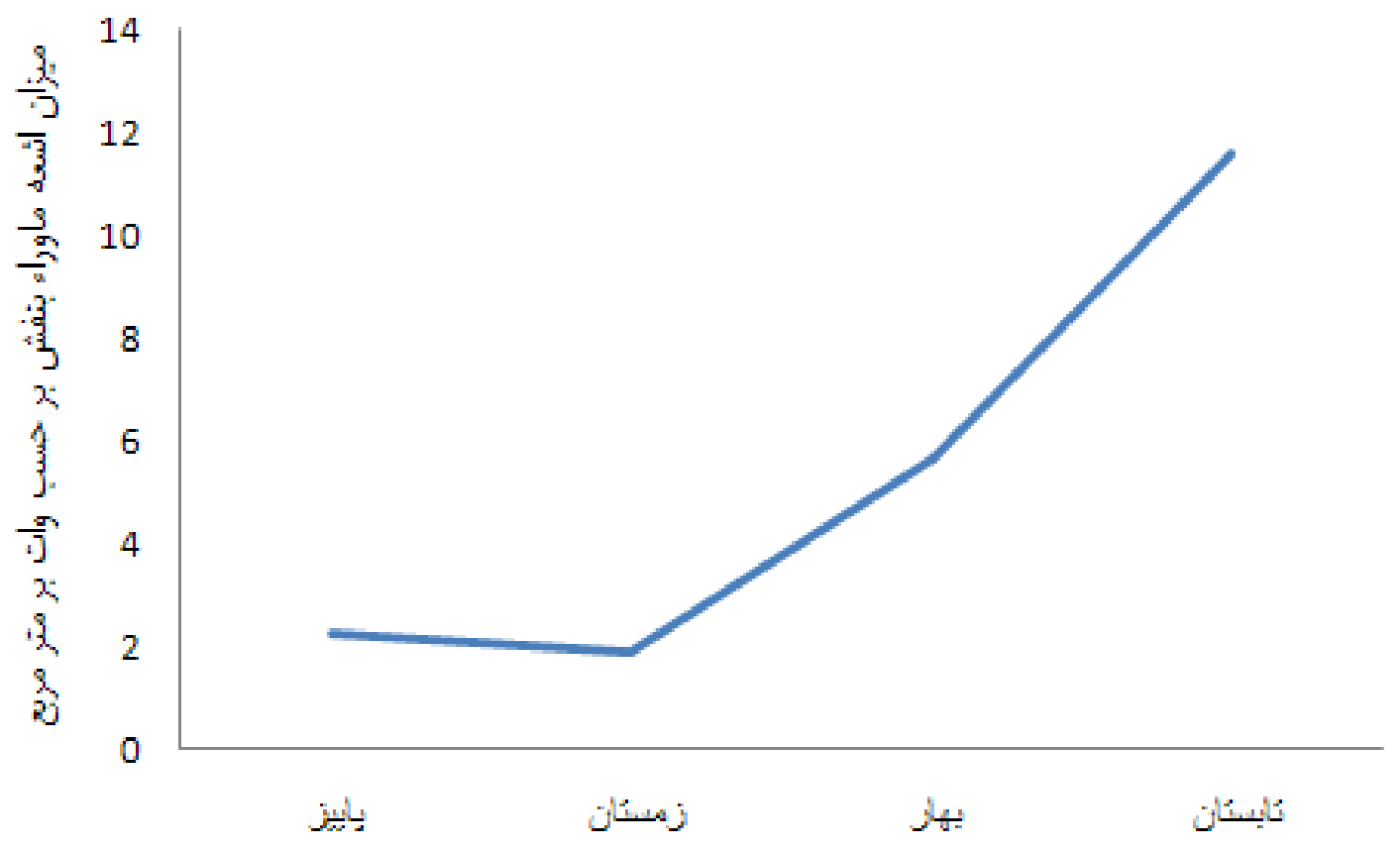

نمودار ا: ميانگين شدت اشعه ماوراء بنفش نوع A بر حسب وات بر متر مربع در فصل هاى مختلف 


\begin{tabular}{|c|c|c|}
\hline ميانگين شدت اشعه بر حسب وات بر متر مربع & ماه & رديف \\
\hline$r / \omega+1 / \Delta$ & مهر & 1 \\
\hline$r / r+1 / r$ & آبان & r \\
\hline$r / r \pm 1 / r$ & آذر & r \\
\hline $1 / 2 \pm 1 / 10$ & s & r \\
\hline$r / l \pm I / \cdot \Delta$ & بهمن & $\Delta$ \\
\hline$r \pm \cdot / 9 \Delta$ & 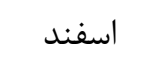 & \& \\
\hline$\Delta / \Delta \pm r / \Delta$ & فروردين & $\checkmark$ \\
\hline$\Delta / 9 \pm T / r$ & ارديبهشت & $\wedge$ \\
\hline$\varphi+r / \Delta$ & 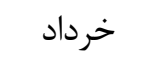 & 9 \\
\hline $11 / 9+1 / 4$ & تير & $1 \cdot$ \\
\hline $1 r+9 / 1$ & 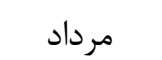 & 11 \\
\hline $11 \pm 9 / 4$ & 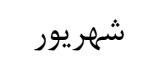 & it \\
\hline
\end{tabular}

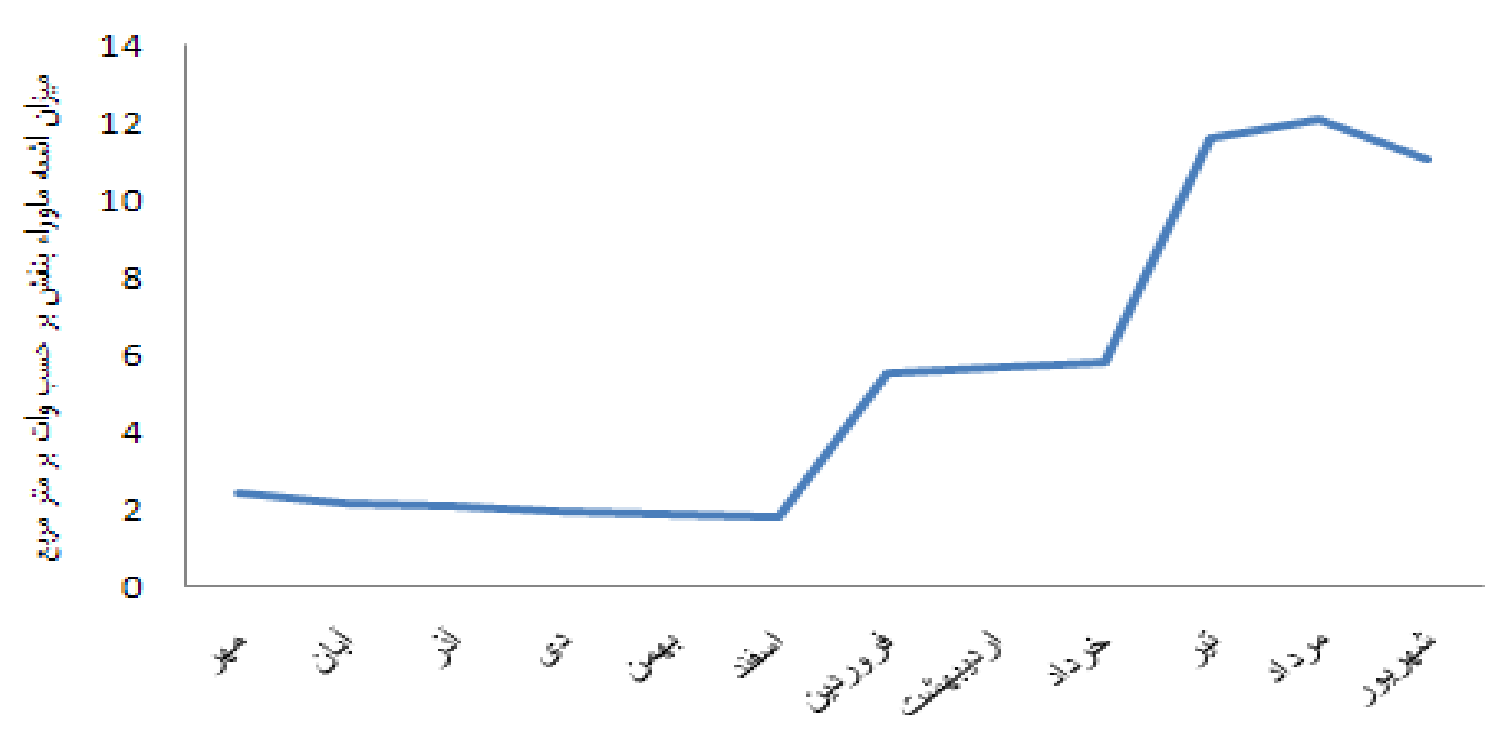

نمودار r: ميانكين شدت اشعه ماوراء بنفش نوع A بر حسب وات بر متر مربع در ماه هاى مختلف 
جدول r: مقدار Pvalue بين شدت اشعه ماوراء بنفش با متغيرها

\begin{tabular}{|c|c|c|}
\hline Pvalue & متغير & رديف \\
\hline$\cdot / \cdots$ & فصل & 1 \\
\hline$\cdot 1 \cdot \cdots$ & ماه & $r$ \\
\hline$\cdot / \cdots$ & زمان(صبح، ظهر و عصر) & r \\
\hline$\cdot 1 \cdot \cdots$ & وضعيت آب و هوايى(ابرى، نيمه ابرى و آفتابى) & f \\
\hline$\cdot / 91 \mathrm{~V}$ & موقعيت جغرافيايى (شمال، جنوب، شرق، غرب و مركز) & $\Delta$ \\
\hline$\cdot / \mathbb{\uparrow} \wedge$ & 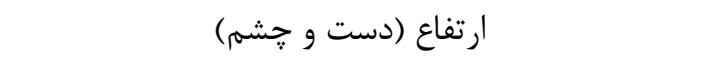 & q \\
\hline
\end{tabular}

زمان ها و ساير وضعيت هاى مختلف آب و هوايى مى باشد بنابراين فراوانى فوتون هاى اشعه ماوراء بنفش در نور خورشيد بيشتر مى باشد. همجنين اختلاف معنادارى بين مقادير شدت اشعه ماوراء بنفش در جهات (9AV) • و ارتفاع هاى مختلف (Pvalue= وجود نداشت. نتايج اندازه گيرى نشان داد كه در طول روز رون

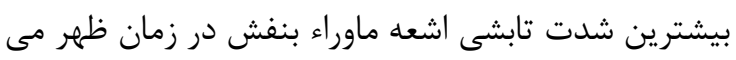
باشد كه ناشى از عمودى تر تابيدن خورشيد در اين زمان

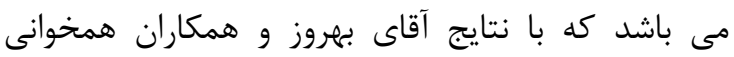

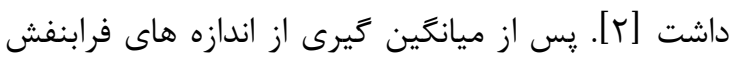

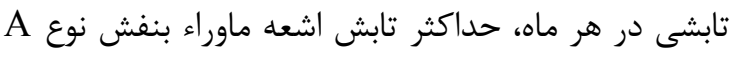

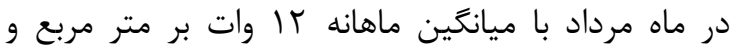

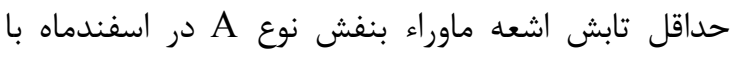

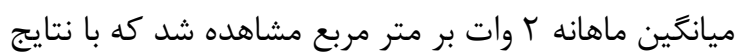

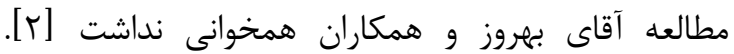

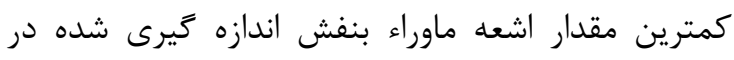

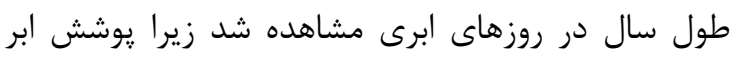
باعث جذب ميزان قابل توجهى از اشعه ماوراء بنفش مى رى

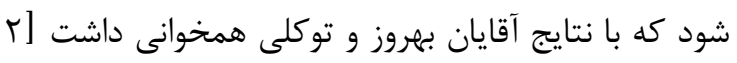

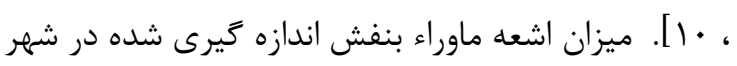

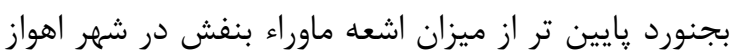
و اصفهان بود كه به دليل شرايط آب و هوايى و شرايط جوى مى باشد به طورى كه شهر بجنورد در شمال شرقى بـ به به

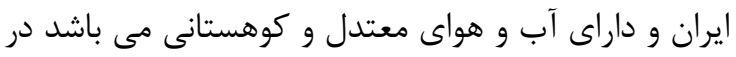
صورتى كه شهرهاى اهواز و اصفهان در جنوب و مركز
شهر بجنورد بر اساس فصل هاى مختلف ( FV اندازه كيرى در هر فصل) نشان داد كه به طور ميانگين ميزان

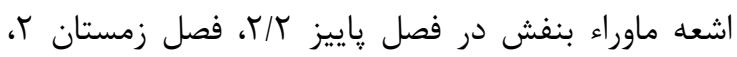

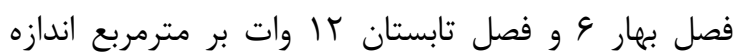
كيرى شد (جدول و نمودار ()). نتايج اندازه كَيرى ميزان

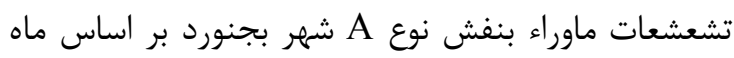
هاى مختلف ( •9 اندازه خيرى در هر ماه) به طور ميانگين بنين ماهانه طى دوره يك ساله در جدول و نمودار (Y) نشان

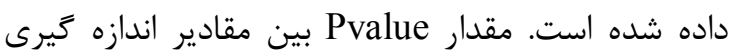

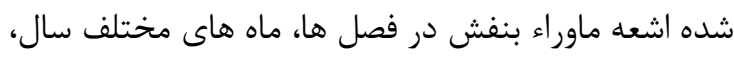

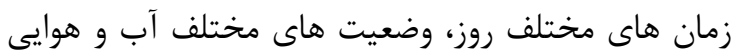
منطقه، موقعيت هاى مختلف جغرافيايى شهر و ارتفاع هاى دست و جشم در جدول (r) نشان داده شده است. بحث با توجه به اين كه حد استاندارد ميزان اشعه ماوراء بنفش نوع A بر اساس استاندارد ACGIH برابر • إسئ وات بر متر

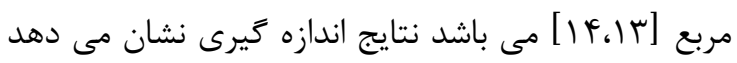
كه ميزان اشعه ماوراء بنفش در فصل تابستان در زمان ظهر و در شرايط آب و هوايى آفتابى بالاتر از حد استاندارد

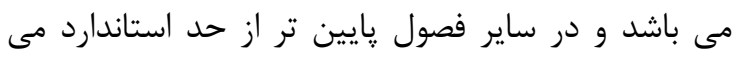

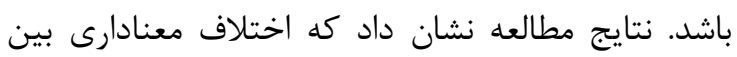
مقادير شدت اشعه ماوراء بنفش در فصل ها، ماه ها، زمانها

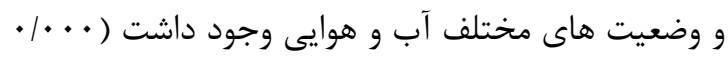

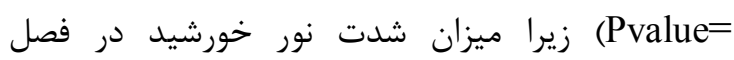
تابستان، زمان ظهر و شرايط آفتابى بيشتر از ساير فصول، نئل 
ثبت كزارش موارد بروز سرطان در استان بيانكر افزايش

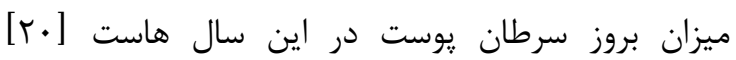
بنابراين با توجه به شدت بالاى نور آفتاب در ماه هاى

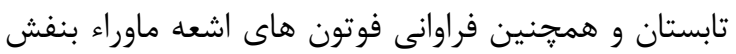
در نور خورشيد بيشنهاد مى شود حتى الامكان ساعات توقف در آفتاب را كاهش داده و از وسايل حفاظت فردى دئن مثل عينك ايمنى، حفاظ هاى صورت و البسه ريزبافت يا جرمى غير قابل نفوذ استفاده شود. كاركرانى كه در فضاى إنى آزاد كار مى كنند مى توانند عينك هاى ايمنى، كرم هاى

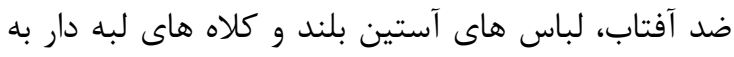

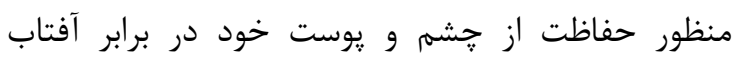
استفاده نمايند. درجه حفاظت كرم هاى ضد خد آفتاب بايستى لا ايا بالاتر باشد. تشكر و قدردانى از معاونت محترم يزوهشى دانشكاه علوم يزشكى خراسان شمالى در تصويب و تامين منابع مالى اين يزوهش (كد بردان

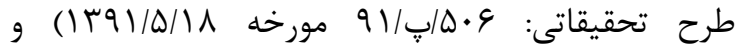
كارشناس آزمايشگاه بهداشت حرفه ائ دابل دانشكده بهداشت

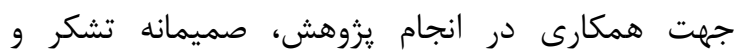

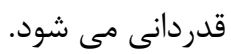

\section{References}

1. Ghazaee S, Disease of Physical Factors in Workplace, Tehran University Press 2005, [Persian]

2. Behrooz MA, Seif F, Fattahi asl J, Behrooz $\mathrm{L}$, Variation of cosmic ultraviolet radiation measurements in Ahvaz at different months of year.Medical knowlage 2010, 9(1):45-51, Jan 12 [Persian]

3. Tirgar A, Kohpaee AR, Alahyari T, Alimohamadi E, Occupational Health, Rafee Andeshe Press 2005 [Persian]

4. AghiliNejad M, Farshad AA, Mostafaei M, Ghafari M, Occupational Medicine Practice, Arjmand Press 2001, ISBN 964-5855-26-8. [Persian]

5. Yosefi HA, Radiation Health, Binesh Azadegan Press 2008. [Persian]

6. Godar DE, UV Doses Worldwide, Photochemistry and Photobiology 81: 736-749, 2005.
ايران قرار كرفته و داراى آب و هواى گرم و خشك مى باشد بنابراين عرض جغرافيايى و شرايط آب و هوايى بر ورائ وائ ميزان شدت اشعه ماوراء بنفش موثر مى باشد. همجنين

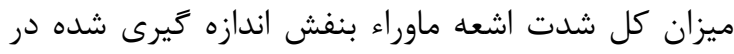
نيوزلند [9]،كشورهاى ساحلى خليج فارس (بحرين، كويت

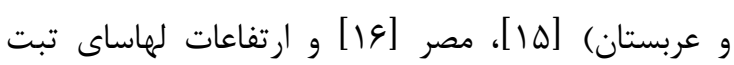
ب [IV]

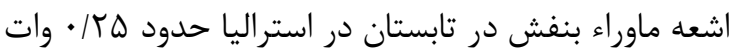
بر متر مربع [N|] و در نيال حدود ك/ / • وات بر متر مربع

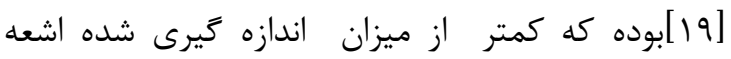
ماوراء بنفش شهر بجنورد مى باشد. از محدوديت هاى اين آندان

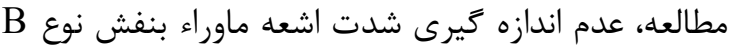
و ميزان اشعه در ساير شهرهاى استان خراسان شمالى مى دي باشد كه يِينهاد مى شود در مطالعات آتى مورد توجه

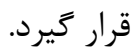
نتيجه كيرى بر اساس آمار واحد بيمارى هاى غيرواگيردار معاونت بهداشتى دانشكاه علوم يزشكى خراسان شمالى، سرطان هاى شايع در استان خراسان شمالى به ترتيب شامل سرطان يوست، سرطان مرى و سرطان معده مى باشد و

7. Hokmabadi R, Khast R, Azadmard Z, Ghiami M, Eghtesadi A, Measurement of cosmic ultraviolet radiation intensity (type A) in Bojnurd, North Khorasan University of Medical Sciences, Tarh Tahghighati NO 506/P/91 [Persian].

8. Gies P, Wright J, Measured Solar Ultraviolet Radiation Exposures of Outdoor Workers in Queensland in the Building and Construction Industry, Photochemistry and Photobiology 78(4): 342-348. 2003.

9. Hammond V, Reeder AI,Gray A, Patterns of real-time occupational ultraviolet radiation exposure among a sample of outdoor workers in new zealand,Public Health Published by Elsevier, pp 182-187.2009.

10. Tavakoli MB, Shahi Z, Solar ultraviolet radiation on the ground level of Isfahan, Iran. J. Radiat Res; 5(2):9, 2007 [Persian].

11. Trabea AA, Salem I, Empirical relationship for ultraviolet solar radiation over Egypt, Egypt J Sol 2001;24(1):123-3. 
12.Bin Mahfoodh M, Al-Ayed MS, Al-Dhafiri AM, Measurement and assessment of ultraviolet radiation in Riyadh, Saudi Arabia, Int J Solar Energy 2003;3:31-8.

13.C. Eugene Moss, Health Hazard Evaluation Report HETA 96-0119-2586, Melroe Company, Bismarck, North Dakota, 1996.

14.Gholmohamadi R," et al", Thershold Limit Value, Tehran University of Medical Sciences, Code 1-0301-2050202, 2012 [Persian].

15.Bin Mahfoodh M, Al-Ayed MS, Al-Dhafiri AM, Measurement and assessment of ultraviolet radiation in Riyadh, Saudi Arabia, Int J Solar Energy 2003 ;3:31-8.

16.Trabea AA, Salem I, Empirical relationship for ultraviolet solar radiation over Egypt, Egypt J Sol 2001;24(1):123-31.

17.Dahlback A, Gelsor N, Stamnes JJ, Gjessing Y. UV measurements in the 3000-
$5000 \mathrm{~m}$ altitude region in Tibet, J Geophys Res 2007;112:1029-34

18. Gies P, Rov C, Javorniczky J, Henderson S, Global solar UV index: Australian measurements, forecasts and comparison with the UK6. 2004;78:281-93.

19. Bhattarai BK, Kjeldstad B, Thorseth TM, Bagheri A, Erythemal dose in Kathmandu, Nepal based on solar UV measurements from multichannel filter radiometer, its deviation from satellite and radiative transfer simulations, J. Atmosres. Res 2007;85:112-9. 20.A review of The reports: The prevalence of cancer in North Khorasan University of Medical Sciences, Available from: URL : http://www.webda.ir/index.aspx?siteid=1\&pag eid $=33149$ \&newsview $=57320$, (Accessed:2011). 
Original Article

\title{
Measurement of cosmic ultraviolet ray intensity (type A) in Bojnurd
}

\author{
Hokmabadi $R A^{1}$, Shoja $E^{2}$ \\ ${ }^{1}$ M.Sc of Occupational Health, Faculty member of Health School, North Khorasan University of Medical \\ Sciences, Bojnurd, Iran \\ ${ }^{2}$ M.Sc of Occupational Health, Faculty member of Health School, North Khorasan University of Medical \\ Sciences, Bojnurd, Iran
}

*Corresponding Author: Health School, North Khorasan University of Medical Sciences, Bojnurd, Iran Email:abi.hes2006@ gmail.com

\begin{abstract}
Background \& Objectives: Sun is the most important natural source of UV light. Exposure to ultraviolet radiation causes harmful effects on the individual. This study aimed to measure the intensity of UV-A in Bojnurd in 2012-13.

Method and Materials: In this cross - sectional study, the intensity of type A ultraviolet ray in Bojnurd was measured in one year by using a Hagner radiometer. Measurements were done in each month, at three time in the morning, afternoon and evening, five geographic directions, in two heights of hand and eye and three weather of sunny, partially cloudy and cloudy. Data were analyzed with SPSS16 software using T-Test and ANOVA test.
\end{abstract}

Results: The results showed that the average intensity of UV rays in the summer is upper than the standard value (10 watts per square meter). The maximum intensity of UV-A was in August with a monthly average of $12 \mathrm{w} / \mathrm{m}^{2}$ and the minimum monthly average was in February with $2 \mathrm{w} / \mathrm{m}^{2}$. The results showed significant difference between the intensity of $U V$ rays in the seasons, months, times and different climatic conditions exist $(P$ $=0.000)$ and difference between the intensity of $U V$ rays in directions $(P=0.987)$ and different heights of body $(P=0.480)$ was not significant.

Conclusions: According to the prevalence and increased incidence of skin cancer in Province in recent years, it is recommended that workers who work outdoors, especially in the summer sun as much as possible to reduce the stopping time and use of appropriate personal protective equipment.

Keywords : UV rays, Ultraviolet type A, Wavelength

Submitted: 15 Oct 2013

Revised: 19 Nov 2013

Accepted:7 Dec 2013 